\title{
Semi-Markov model for the Kaplan preventive repair system for water turbines with periodic inspection of the technical condition
}

\author{
Klaudiusz Migawa*, Agnieszka Sołtysiak, Magda Czyżewska, Sylwester Borowski and \\ Maciej Woropay \\ Bydgoszcz University of Science and Technology, Faculty of Mechanical Engineering, 85-796 \\ Bydgoszcz, Poland
}

\begin{abstract}
The paper presents a semi-Markow model of a preventive repair system by age, implemented in hydroelectric power plants with Kaplan turbines. In the case of the analyzed technical objects, the profit per time unit is considered as the criterion of the quality of functioning. On the basis of the adopted assumptions, for the developed mathematical model, formulas describing the criterion function were determined and the conditions for the existence of the extreme (maximum) of this function were formulated. The proposed method makes it possible to determine the optimal time for preventive repair of the considered technical objects. The theoretical considerations presented in the work are illustrated by a computational example developed on the basis of data obtained from the actual operating system of Kaplan water turbines with a rated power of $120 \mathrm{~kW}$.
\end{abstract}

\section{Introduction}

Proper and effective operation of hydropower plants is possible only if the continuity of electricity production is ensured. The main reasons for interruptions in the production process are the impact of natural conditions (water flow intensity) and the need for corrective repairs (CM) after damage to water turbines. This results in additional costs related to the implementation of corrective repairs and costs caused by unplanned downtime. One of the methods of increasing the efficiency of operation of this type of exploitation systems is the introduction of the preventive repair system (PM). It consists in planning the dates and scope of preventive actions in such a way that their costs are lower than the costs of repairs after damage. Determining an appropriate repair schedule is associated with the need to periodically assess the technical condition of the facilities in use. For this purpose, the influence of selected operational factors on the parameters of their work is examined. Examples of research are presented in the works [1-3]. For this reason, determining the optimal times of preventive repairs of technical facilities is a significant problem in planning the strategy of operation in operating systems.

Corrective repairs of technical facilities, as well as preventive repairs, can be implemented in practice in two variants. First, as fine repairs (PR). After such a repair, the

* Corresponding author: klaudiusz.migawa@pbs.edu.pl 
technical object is "As-Good-As-New" (AGAN). Secondly, as minimal repairs (MR). As a result, after repair, the technical object is "As-Bad-As-Old" (ABAO). For the first time, the concept of minimal repair in relation to the reliability theory was used in [4].

It is assumed in this paper that after each minimal repair, the damaged technical object is only restored to the same failure state as before the damage. The authors of work [5] consider the issue of minimal repair assuming that a thorough repair is performed with the probability $p$, while the minimal repair is performed with the probability $q=1-p$. An overview of various ways of modeling systems with minimal repairs and the construction of criterion functions is presented in works $[6,7]$. These works describe and classify models of maintenance strategies for technical facilities for both finite and infinite time horizons, in which the criterion functions are total costs, unit costs, reliability and availability. In real maintenance systems for technical facilities, the effectiveness of repairs is between AGAN and ABAO. This applies to the so-called inaccurate maintenance and repair of technical facilities. The methods for preventive repairs and replacements, in which the repair mechanism with an inaccurate maintenance model with the $(\mathrm{p}, \mathrm{q})$ rule is applied, is widely discussed in [6]. Models of imperfect maintenance systems with the use of different age replacement policies have also been widely presented in the literature. For example, in [8] the authors consider the replacement policy depending on the age of the system and the minimization of repair costs. In other works, the policies in which model parameters are assumed to be random are considered, eg in [9] random repair costs are assumed. On the other hand, the article [10] describes the policy of replacement by age, in which the probability of an exact repair is a random variable with a specific distribution, and the criterion function is the cost of repair per time unit. The results presented in this paper are a continuation of the considerations presented in [11-13], in which the results were obtained on the basis of the research of semiMarkov models, in which the profit of the exploitation system or the cost of preventive replacement per time unit were considered as criterion functions.

The purpose of this manuscript is to develop and examine a 5-state semi-Markov model of preventive repairs with the use of periodic assessment of the technical condition of the technical facilities in use. The object of research in this work is the Kaplan water turbine operation system with a rated power of $120 \mathrm{~kW}$, and the considered criterion function is the system profit per unit of time, determined in an infinite time horizon. In the developed model, the basis for building the criterion function is the limit theorem for semi-Markov processes [14]. The results of the model tests, developed on the basis of real data, may constitute the basis for making decisions in the analyzed exploitation system.

\subsection{States in the Kaplan water turbine operation model}

The technical object considered in the manuscript - a water power plant with a Kaplan turbine - may be in one of five states of the considered model of the exploitation process:

- state 1 - task implementation state - state of electricity production,

- state 2 - state of downtime (breaks) in the implementation of the task due to natural conditions,

- state 3 - state of waiting for diagnostics and corective maintenance - after a fault has occurred,

- state 4 - the state of diagnosis and corective maintenance - after a fault has occurred,

- state 5 - the state of diagnosis and preventive repair - this is the state when a serviceable technical object is subject to preventive diagnosis and repair after a specific hourly mileage and in accordance with the adopted operational strategy.

Figure 1 shows a graph intended to map changes in the operational process model of the considered technical object (Kaplan water turbine). 


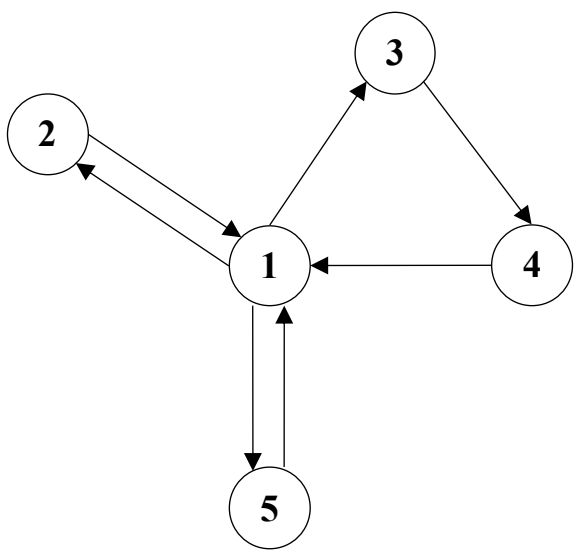

Fig. 1. Directed graph representing changes in the states of the Kaplan water turbine operation process model with the state space $S=\{1,2,3,4,5\}$.

\subsection{Mathematical model for the operation of Kaplan water turbines}

For the directed graph presented in Figure 1, a mathematical model was built assuming that it is the stochastic process $\mathrm{X}(\mathrm{t})$. The mathematical model was developed using the theory of semi-Markov processes $[14,15]$.

The manuscript considers a 5 -state semi-Markovian model for the exploitation process of Kaplan water turbines with the state space $S=\{1,2,3,4,5\}$. If $X(t)=i$, then the considered technical object at time $t$ is in the state $i$. The transition matrix of the Markov chain inserted into the semi-Markov process for the model under consideration has the form

$$
\mathrm{P}=\left[\begin{array}{ccccc}
0 & \mathrm{p}_{12} & \mathrm{p}_{13} & 0 & \mathrm{p}_{15} \\
\mathrm{p}_{21} & 0 & 0 & 0 & 0 \\
0 & 0 & 0 & \mathrm{p}_{34} & 0 \\
\mathrm{p}_{41} & 0 & 0 & 0 & 0 \\
\mathrm{p}_{51} & 0 & 0 & 0 & 0
\end{array}\right]
$$

where

$\mathrm{p}_{\mathrm{ij}}, \mathrm{i}, \mathrm{j}=1,2,3,4,5$ - probability of transition from state $\mathrm{i}$ to state $\mathrm{j}$.

In order to determine the limit probabilities for the Markov chain, the following matrix system should be solved:

$$
\left[\begin{array}{ccccc}
0 & \mathrm{p}_{21} & 0 & \mathrm{p}_{41} & \mathrm{p}_{51} \\
\mathrm{p}_{12} & 0 & 0 & 0 & 0 \\
\mathrm{p}_{13} & 0 & 0 & 0 & 0 \\
0 & 0 & \mathrm{p}_{34} & 0 & 0 \\
\mathrm{p}_{15} & 0 & 0 & 0 & 0
\end{array}\right] \cdot\left[\begin{array}{c}
\pi_{1} \\
\pi_{2} \\
\pi_{3} \\
\pi_{4} \\
\pi_{5}
\end{array}\right]=\left[\begin{array}{c}
\pi_{1} \\
\pi_{2} \\
\pi_{3} \\
\pi_{4} \\
\pi_{5}
\end{array}\right]
$$

where

$\pi_{\mathrm{i}}, \mathrm{i}=1,2,3,4,5$ - boundary probability of the Markov chain put into the semi-Markov process. 
The paper considers a model in which a technical object is diagnosed and preventively repaired at age $T$ or diagnosed and corrected when damaged, whichever comes first. The time to preventive repair or damage (corrective repair) of a technical object is defined by $\mathrm{T}_{1}(\mathrm{x})$. The variable $T_{1}(x)$ is defined as follows

$$
\mathrm{T}_{1}(\mathrm{x})=\left\{\begin{array}{lll}
\mathrm{T}_{1}, & \text { gdy } & \mathrm{T}_{1}<\mathrm{x} \\
\mathrm{x}, & \text { gdy } & \mathrm{T}_{1} \geq \mathrm{x}
\end{array}\right.
$$

It is assumed that after the lapse of time $\mathrm{x}$, if the technical object is not damaged, it enters the preventive repair state. The process of state changes $i=1,2,3,4,5$, taking into account the preventive repair over time $\mathrm{x}$ is a new semi-Markov process with the $\mathrm{P}(\mathrm{x})$ matrix of the transition probabilities of the Markov chain inserted into the semi-Markov process. With reference to the matrix $\mathrm{P}(1)$ presented above, only the first row of the matrix $\mathrm{P}$ changes, then the matrix $\mathrm{P}(\mathrm{x})$ takes the form

$$
\mathrm{P}(\mathrm{x})=\left[\begin{array}{ccccc}
0 & \mathrm{p}_{12}(\mathrm{x}) & \mathrm{p}_{13}(\mathrm{x}) & 0 & \mathrm{p}_{15}(\mathrm{x}) \\
\mathrm{p}_{21} & 0 & 0 & 0 & 0 \\
0 & 0 & 0 & \mathrm{p}_{34} & 0 \\
\mathrm{p}_{41} & 0 & 0 & 0 & 0 \\
\mathrm{p}_{51} & 0 & 0 & 0 & 0
\end{array}\right]
$$

while the limit probabilities determined for the Markov chain are presented below:

$$
\begin{gathered}
\pi_{1}(\mathrm{x})=\frac{1}{\mathrm{~m}} \\
\pi_{2}(\mathrm{x})=\frac{\mathrm{p}_{12}(\mathrm{x})}{\mathrm{m}} \\
\pi_{3}(\mathrm{x})=\frac{\mathrm{p}_{13}(\mathrm{x})}{\mathrm{m}} \\
\pi_{4}(\mathrm{x})=\frac{\mathrm{p}_{13}(\mathrm{x}) \cdot \mathrm{p}_{34}}{\mathrm{~m}} \\
\pi_{5}(\mathrm{x})=\frac{\mathrm{p}_{15}(\mathrm{x})}{\mathrm{m}}
\end{gathered}
$$

where

$\mathrm{m}=1+\mathrm{p}_{12}(\mathrm{x})+\mathrm{p}_{13}(\mathrm{x}) \cdot\left(1+\mathrm{p}_{34}\right)+\mathrm{p}_{15}(\mathrm{x})$

\section{Determination of the criterion function}

The paper analyzes the semi-Markovian model of preventive repairs by age. A 5 -state semiMarkovian process $X(t)$ with the state space $S=\{1,2,3,4,5\}$ is considered. By $z_{i}, i=1,2$, $3,4,5$ is denoted the unit profit (cost) (per time unit) for the state $i$. It is assumed in the paper that $\mathrm{z}_{1}>0, \mathrm{z}_{\mathrm{i}}<0$ for $\mathrm{i}=2,3,4,5$. It means that if the technical object is in state 1 , profit is generated, while if the technical object is in state $i=2,3,4,5$, then cost (loss) is generated.

On the basis of article [12], for the considered model of the preventive repair system, the criterion function describing the total profit (loss) per unit of time is expressed by the formula 


$$
\mathrm{g}(\mathrm{x})=\frac{\pi_{1}(\mathrm{x}) \cdot \mathrm{ET}_{1}(\mathrm{x}) \cdot \mathrm{z}_{1}+\sum_{\mathrm{i}=2}^{5} \pi_{\mathrm{i}}(\mathrm{x}) \cdot \mathrm{ET}_{\mathrm{i}} \cdot \mathrm{z}_{\mathrm{i}}}{\pi_{1}(\mathrm{x}) \cdot \mathrm{ET}_{1}(\mathrm{x})+\sum_{\mathrm{i}=2}^{5} \pi_{\mathrm{i}}(\mathrm{x}) \cdot \mathrm{ET}_{\mathrm{i}}}
$$

where

$\mathrm{ET}_{1}(\mathrm{x})$ - mean value of the residence time in state 1 , calculated from the formula $[1,2]$

$$
\operatorname{ET}_{1}(\mathrm{x})=\int_{0}^{\mathrm{x}} \mathrm{R}_{1}(\mathrm{t}) \mathrm{dt}
$$

$\mathrm{ET}_{2}, \mathrm{ET}_{3}, \mathrm{ET}_{4}, \mathrm{ET}_{5}$ - the mean values of the residence times in the states, respectively 2, 3, $4,5$.

In particular, on the basis of the article [3] can be written:

$$
\begin{aligned}
& \mathrm{p}_{12}(\mathrm{x})=\mathrm{p}_{12} \cdot \mathrm{F}_{12}(\mathrm{x}) \\
& \mathrm{p}_{13}(\mathrm{x})=\mathrm{p}_{13} \cdot \mathrm{F}_{13}(\mathrm{x}) \\
& \mathrm{p}_{15}(\mathrm{x})=\mathrm{p}_{15} \cdot \mathrm{F}_{15}(\mathrm{x})+\mathrm{R}_{1}(\mathrm{x})
\end{aligned}
$$

where:

$F_{1 j}(x), j=2,3,5$ - conditional cumulative distribution function of the residence time in state 1 , provided that the next state is state $\mathrm{j}$;

$\mathrm{R}_{1}(\mathrm{x})=1-\mathrm{F}_{1}(\mathrm{x})-$ random variable reliability function $\mathrm{T}_{1}$.

Additionally, in order to simplify further considerations, it was assumed that the equals are true

$$
\mathrm{F}_{12}(\mathrm{x})=\mathrm{F}_{13}(\mathrm{x})=\mathrm{F}_{15}(\mathrm{x})=\mathrm{F}_{1}(\mathrm{x})
$$

Taking the above into account, the criterion function (6) is expressed by the formula

$$
\mathrm{g}(\mathrm{x})=\frac{\mathrm{ET}_{1}(\mathrm{x}) \cdot \mathrm{z}_{1}+\left[\mathrm{p}_{12} \cdot \mathrm{ET}_{2} \cdot \mathrm{z}_{2}+\mathrm{p}_{13} \cdot\left(\mathrm{ET}_{3} \cdot \mathrm{z}_{3}+\mathrm{ET}_{4} \cdot \mathrm{z}_{4}\right)-\left(1-\mathrm{p}_{15}\right) \cdot \mathrm{ET}_{5} \cdot \mathrm{z}_{5}\right] \cdot \mathrm{F}_{1}(\mathrm{x})+\mathrm{ET}_{5} \cdot \mathrm{z}_{5}}{\mathrm{ET}_{1}(\mathrm{x})+\left[\mathrm{p}_{12} \cdot \mathrm{ET}_{2}+\mathrm{p}_{13} \cdot\left(\mathrm{ET}_{3}+\mathrm{ET}_{4}\right)-\left(1-\mathrm{p}_{15}\right) \cdot \mathrm{ET}_{5}\right] \cdot \mathrm{F}_{1}(\mathrm{x})+\mathrm{ET}_{5}}
$$

\subsection{Conditions of existence of the maximum of the criterion function - profit per time unit}

The conditions for the existence of the extremum (maximum) of the criterion function (6) will be formulated depending on the parameters of the developed semi-Markovian model for the Kaplan water turbine operation process. This is for the elements of the probability matrix of changes in the model states $\mathrm{P}=\left[\mathrm{p}_{\mathrm{ij}}\right], \mathrm{i}, \mathrm{j}=1,2,3,4,5$, the average residence times in the $E_{i}$ model states and unit profits (costs) generated in the model states $z_{i}, i=1,2,3,4,5$. The considered parameters constitute the input data of the model, and their values depend on the type and type of the analyzed technical objects, the adopted operation strategy and specific operating conditions in which corrective repairs and preventive repairs are carried out.

Assumptions concerning the values of the parameters of the tested system are specified below. The adopted assumptions must take into account the actual relations between the parameters characterizing the performed corrective repairs of damaged technical objects and preventive repairs: 
- Z1: $z_{1}>0, z_{i}<0$, dla $i=2,3,4,5$

- $\mathrm{Z} 2: \mathrm{Z}_{5}<\mathrm{Z}_{4}$

- Z3: $\mathrm{z}_{2}<\mathrm{z}_{5}<\mathrm{z}_{4}$

- Z4: $\mathrm{z}_{3}<\mathrm{z}_{5}<\mathrm{z}_{4}$

- Z5: $\mathrm{ET}_{3}+\mathrm{ET}_{4}>\mathrm{ET}_{5}$;

- Z6: $\mathrm{ET}_{3}+\mathrm{ET}_{4}>\mathrm{ET}_{2}$.

The above assumptions do not define all relationships between unit costs and average times. For example, the relationship between $z_{2}$ and $z_{3}$ and $E_{2}$ and $E_{5}$ has not been established. In the analyzed system, it is very difficult to unambiguously define the relationship between the average values of these times. In the further part of the work, in order to formulate the conditions for the existence of the maximum of the criterion function (6), additional conditions were defined using formulas (14) and (17).

The criterion function (6) can be presented as follows

where:

$$
\mathrm{g}(\mathrm{x})=\frac{\mathrm{L}(\mathrm{x})}{\mathrm{M}(\mathrm{x})}=\frac{\mathrm{A}_{1} \cdot \mathrm{ET}_{1}(\mathrm{x})+\mathrm{B}_{1} \cdot \mathrm{F}_{1}(\mathrm{x})+\mathrm{C}_{1}}{\mathrm{~A} \cdot \mathrm{ET}_{1}(\mathrm{x})+\mathrm{B} \cdot \mathrm{F}_{1}(\mathrm{x})+\mathrm{C}}
$$

$$
\begin{aligned}
& \mathrm{A}_{1}=\mathrm{z}_{1} \\
& \mathrm{~B}_{1}=\mathrm{p}_{12} \cdot \mathrm{ET}_{2} \cdot \mathrm{z}_{2}+\mathrm{p}_{13} \cdot\left(\mathrm{ET}_{3} \cdot \mathrm{z}_{3}+\mathrm{ET}_{4} \cdot \mathrm{z}_{4}\right)-\left(1-\mathrm{p}_{15}\right) \cdot \mathrm{ET}_{5} \cdot \mathrm{z}_{5} \\
& \mathrm{C}_{1}=\mathrm{ET}_{5} \cdot \mathrm{z}_{5} \\
& \mathrm{~A}=1 \\
& \mathrm{~B}=\mathrm{p}_{12} \cdot \mathrm{ET}_{2}+\mathrm{p}_{13} \cdot\left(\mathrm{ET}_{3}+\mathrm{ET}_{4}\right)-\left(1-\mathrm{p}_{15}\right) \cdot \mathrm{ET}_{5} \\
& \mathrm{C}=\mathrm{ET}_{5}
\end{aligned}
$$

In order to determine the conditions of existence of the maximum of the criterion function, the following coefficients were introduced:

$$
\begin{gathered}
\alpha=\mathrm{A} \mathrm{B}_{1}-\mathrm{A}_{1} \mathrm{~B} \\
\beta=\mathrm{A}_{1} \mathrm{C}-\mathrm{A} \mathrm{C}_{1} \\
\gamma=\mathrm{B}_{1} \mathrm{C}-\mathrm{B} \mathrm{C}_{1}
\end{gathered}
$$

The coefficients $\alpha, \beta$ and $\gamma$ play an important role in the formulation of sufficient conditions for the existence of extremes of the criterion function. For this purpose, the following conditions are formulated sufficiently to make the inequalities $\alpha<0, \beta>0, \gamma<0$ true.

Having regard to the above considerations:

- the $\alpha$ coefficient is given by the formula

$$
\alpha=\mathrm{p}_{12} \mathrm{ET}_{2}\left(\mathrm{z}_{2}-\mathrm{z}_{1}\right)+\mathrm{p}_{13}\left[\mathrm{ET}_{3}\left(\mathrm{z}_{3}-\mathrm{z}_{1}\right)+\mathrm{ET}_{4}\left(\mathrm{z}_{4}-\mathrm{z}_{1}\right)\right]+\left(1-\mathrm{p}_{15}\right) \mathrm{ET}_{5}\left(\mathrm{z}_{1}-\mathrm{z}_{5}\right)_{(13)}
$$

Nierówność $\alpha<0$ jest równoważna nierówności

$$
\mathrm{ET}_{5}<\frac{\mathrm{p}_{12} \cdot \mathrm{ET}_{2} \cdot\left(\mathrm{z}_{2}-\mathrm{z}_{1}\right)+\mathrm{p}_{13} \cdot\left[\mathrm{ET}_{3} \cdot\left(\mathrm{z}_{3}-\mathrm{z}_{1}\right)+\mathrm{ET}_{4} \cdot\left(\mathrm{z}_{4}-\mathrm{z}_{1}\right)\right]}{\left(1-\mathrm{p}_{15}\right) \cdot\left(\mathrm{z}_{5}-\mathrm{z}_{1}\right)}
$$

- the $\beta$ coefficient is given by the formula

$$
\beta=\mathrm{ET}_{5}\left(\mathrm{z}_{1}-\mathrm{z}_{5}\right)
$$


On the basis of the adopted assumption $Z_{1}$ it follows that $\beta>0$.

- the $\gamma$ factor is given by the formula

$$
\gamma=\left[\mathrm{p}_{12} \mathrm{ET}_{2}\left(\mathrm{z}_{2}-\mathrm{z}_{5}\right)+\mathrm{p}_{13}\left[\mathrm{ET}_{3}\left(\mathrm{z}_{3}-\mathrm{z}_{5}\right)+\mathrm{ET}_{4}\left(\mathrm{z}_{4}-\mathrm{z}_{5}\right)\right] \mathrm{ET}_{5}\right.
$$

The inequality $\gamma<0$ is equivalent to the inequality

$$
\mathrm{z}_{5}>\frac{\mathrm{p}_{12} \cdot \mathrm{ET}_{2} \cdot \mathrm{z}_{2}+\mathrm{p}_{13} \cdot\left(\mathrm{ET}_{3} \cdot \mathrm{z}_{3}+\mathrm{ET}_{4} \cdot \mathrm{z}_{4}\right)}{\mathrm{p}_{12} \cdot \mathrm{ET}_{2}+\mathrm{p}_{13} \cdot\left(\mathrm{ET}_{3}+\mathrm{ET}_{4}\right)}
$$

Based on the equations and inequalities presented by the formulas (13), (14), (16) and (17), conclusions 1 and 2 can be formulated:

Conclusion 1. If the condition given by the formula (14) is satisfied, then the inequality $\alpha<0$ is true.

Conclusion 2. If the condition given by the formula (17) is satisfied, then the inequality $\gamma<0$ is true.

Sufficient conditions for the existence of the maximum of the criterion function will be formulated below (6). The class of random variable distributions with unimodal failure intensity function, i.e. $T_{1} \in$ MTFR (Mean Time to Failure or Repair) is considered. Additionally, the considerations concern the class of random variable distributions for which it is assumed that the time to failure of the technical object $\mathrm{T} 1$ is a random variable with an increasing failure intensity function $\lambda 1(t)$, i.e. $T_{1} \in$ IFR (Increasing Failure Rate). The results of research on the properties of the distribution of a random variable of the MTFR class are presented in detail in [16-18], while the conditions for the existence of a maximum of the criterion function (6) were formulated and discussed in the papers [12, 13].

Conclusion 3. If $T_{1} \in \mathrm{IFR}, \lambda 1(\mathrm{t})$ is differentiable, $\alpha<0, \beta>0, \gamma<0, \beta+\gamma \mathrm{f}_{1}\left(0^{+}\right)>0, \lambda_{1}(\infty) \alpha$ $\mathrm{ET}_{1}+\beta-\alpha<0$, then the criterion function $\mathrm{g}(\mathrm{x})$ reaches its maximum value.

Proof.

The derivative of the criterion function $\mathrm{g}(\mathrm{x})$ has the form

$$
\mathrm{g}^{\prime}(\mathrm{x})=\frac{\alpha \cdot\left[\mathrm{f}_{1}(\mathrm{x}) \cdot \mathrm{ET}_{1}(\mathrm{x})-\mathrm{R}_{1}(\mathrm{x}) \cdot \mathrm{F}_{1}(\mathrm{x})\right]+\beta \cdot \mathrm{R}_{1}(\mathrm{x})+\gamma \cdot \mathrm{f}_{1}(\mathrm{x})}{\mathrm{M}^{2}(\mathrm{x})}
$$

where $\mathrm{M}(\mathrm{x})$ is the denominator of the criterion function $\mathrm{g}(\mathrm{x})$.

It is known that if the time to failure $T_{1}$ belongs to the MTFR random variable distribution class, then the equation $\mathrm{H}(\mathrm{x})=\lambda_{1}(\mathrm{x}) \mathrm{ET}_{1}(\mathrm{x})-\mathrm{F}_{1}(\mathrm{x}) \geq 0$ for $\mathrm{x} \geq 0$ is true. The MTFR class includes some life time distributions with a unimodal damage intensity function. The MTFR random variable distribution class has been examined in articles $[17,18]$. From the fact that the derivative $\mathrm{H}^{\prime}(\mathrm{x})=\lambda_{1}{ }^{\prime}(\mathrm{x}) \mathrm{ET}_{1}(\mathrm{x})$ it follows that if the failure intensity function $\lambda_{1}(\mathrm{t})$ increases, then the function $\mathrm{H}(\mathrm{x})$ also increases. The class of random variable distributions with the non-decreasing failure intensity function (IFR) is included in the MTFR class. The derivative sign is the same as the function sign

$$
\mathrm{h}(\mathrm{x})=\alpha \cdot\left[\lambda_{1}(\mathrm{x}) \cdot \mathrm{ET}_{1}(\mathrm{x})-\mathrm{F}_{1}(\mathrm{x})\right]+\beta+\gamma \cdot \lambda_{1}(\mathrm{x})_{(19)}
$$


It is known that $\mathrm{H}\left(0^{+}\right)=0$, hence $\mathrm{h}\left(0^{+}\right)=\beta+\gamma \mathrm{f}_{1}\left(0^{+}\right)>0$. From the fact that $\alpha<0, \beta>0, \gamma<0$ and the function $\mathrm{H}(\mathrm{x})$ grows it follows that the function $\mathrm{h}(\mathrm{x})$ decreases from the value $\mathrm{h}\left(0^{+}\right)$ $=\beta+\gamma \mathrm{fl}\left(0^{+}\right)>0$ to the value $\mathrm{h}(\infty)=\lambda_{1}(\infty) \alpha \mathrm{ET}_{1}+\beta-\alpha<0$. It follows that the derivative of $\mathrm{g}^{\prime}(\mathrm{x})$ changes the sign from "+" to "-" exactly once. Hence, it is concluded that the criterion function $\mathrm{g}(\mathrm{x})$ reaches exactly one maximum.

If $\lambda_{1}(\infty)=\infty$, then the following conditions are sufficient for the existence of the maximum of the criterion function $\mathrm{g}(\mathrm{x})$ : $\mathrm{T}_{1} \in \mathrm{IFR}$, differentiability $\lambda_{1}(\mathrm{t}), \alpha<0, \beta>0, \gamma<0, \beta+\gamma \mathrm{f}_{1}\left(0^{+}\right)>0$. An example of such a distribution of a random variable is the Weibull distribution with an increasing damage intensity function.

The conclusions 1, 2 and 3 show the following sufficient condition for the existence of the maximum of the criterion function $\mathrm{g}(\mathrm{x})$ - profit per time unit:

Conclusion 4. If $\mathrm{T}_{1} \in \mathrm{IFR}, \lambda_{1}(\mathrm{t})$ is differentiable, $\beta+\gamma \lambda_{1}\left(0^{+}\right)>0, \lambda_{1}(\infty) \alpha \mathrm{ET}_{1}+\beta-\alpha<0$ and conditions (11) and (14) are met, then the criterion function $\mathrm{g}(\mathrm{x})$ reaches its maximum value.

\section{Sample test results}

Figure 2 shows the graphs of the criterion function $\mathrm{g}(\mathrm{x})$ - profit per unit of time [PLN $\cdot 103$ / month] as a function of time to preventive repair $\mathrm{x}$ [months], determined for the technical object under consideration - Kaplan water turbine with a capacity of $120 \mathrm{~kW}$. The calculations were made for the following data:

1) values of the probability matrix of changes in the states of the P model:

$$
\mathrm{P}=\left[\begin{array}{ccccc}
0 & 0.65 & 0.19 & 0 & 0.16 \\
1 & 0 & 0 & 0 & 0 \\
0 & 0 & 0 & 1 & 0 \\
1 & 0 & 0 & 0 & 0 \\
1 & 0 & 0 & 0 & 0
\end{array}\right]
$$

2) average values of the times of the technical object's stay in the states for the operation process model in $[\mathrm{h}]: \mathrm{ET}_{2}=4, \mathrm{ET}_{3}=17, \mathrm{ET}_{4}=11, \mathrm{ET}_{5}=8$; for the validity time $\mathrm{T}_{1}$, the Weibull distribution was assumed, for which the value of the scale parameter scale $=9$; three cases were analyzed where the value of the shape parameter of the Weibull distribution is appropriately shape $\in\{8,9.5,11\}$;

3) average values of profits (costs) per time unit in individual states of the model in $\left[\mathrm{PLN} \cdot 10^{3} /\right.$ day]: $\mathrm{z}_{1}=0.38, \mathrm{z}_{2}=-0.17, \mathrm{z}_{3}=-0.17, \mathrm{z}_{4}=-4.7, \mathrm{z}_{5}=-2.6$. 


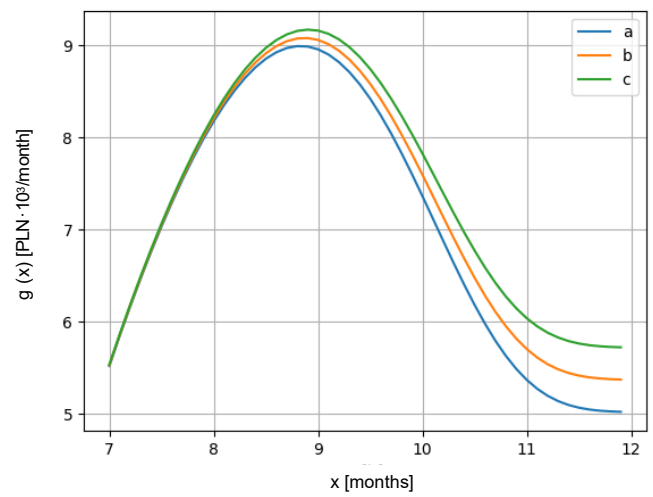

Fig. 2. Graphs of the function $\mathrm{g}(\mathrm{x})$ - profit per time unit [PLN 103 / month] as a function of time to preventive repair $\mathrm{x}$ [months], determined for the Weibull distribution with the following parameters: scale $=9$ and shape $=8,9.5,11$ (respectively curves a, b, c).

\section{Conclusions}

The considerations presented in the paper allowed for the development of a mathematical model of preventive repairs of Kaplan water turbines. The model was built using semiMarkov processes. In the developed model, the criterion function is considered in an infinite time horizon. On the basis of the conducted analysis, sufficient conditions for the existence of the maximum of this function were formulated, when the time of correct operation is a random variable with an increasing failure intensity function.

On the basis of the obtained graphs (shown in Figure 2), it can be concluded that for individual values of the Weibull distribution shape parameter, the criterion function $\mathrm{g}(\mathrm{x})$ profit per time unit - under consideration in this work - reaches the extreme. In each of the three analyzed cases, there is an optimal value of the time to preventive repair xmax [months], for which the criterion function $\mathrm{g}(\mathrm{x})\left[\mathrm{PLN} \cdot 10^{3} / \mathrm{month}\right]$ reaches its maximum value. Analyzing the obtained results, it can be noticed that with increasing the value of the shape parameter, the maximum value of profit per time unit increases with very similar values of time to preventive repair $\mathrm{x}_{\max }=8.8 \div 8.9$ months.

The assumptions adopted in the model and formulated conditions define the relations between the input parameters of the developed model and verify the possibility of using a specific set of input data to determine the maximum of the considered criterion function. The developed model of the preventive repair system can be used to determine the optimal strategies of preventive actions in the operation systems of technical facilities of a similar class. The presented research results constitute the next stage of work on modeling the operation systems of technical facilities, in which preventive replacements by age are carried out.

\section{References}

1. M. Markiewicz, Ł. Muslewski, The impact of powering an engine with fuels from reneweble energy sources inclouding its softwere modification on a drive unit performance parameters. Sustainaibility 11, 23 (2019)

2. J. Wilczarska, E. Kulis, M. Łukasiewicz, Ł. Fornal, N. Dluhunovych, The assessment of the impact of the chosen exploational conditions of hydraulic arrangement on the 
working liquid condition, 17th International Conference Diagnostics of Machines and Vehicles Book Series, MATEC Web of Conferences, 182, 01026 (2018)

3. T. Kałaczyński, V. Martynyuk, J. Boiko, S. Matyukh, S. Petrashchuk, Exploitation aspects of diagnostic hydraulic and pneumatic systems of Multimedia Hybrid Mobile Stages, 19th International Conference Diagnostics of Machines and Vehicles Hybrid Multimedia Mobile Stage (2021)

4. R. Barlow, L. Hunter, Oper. Res, Optimum preventive maintenance policies, 8, 90-110 (1960)

5. M. Brown, F. Proschan, J Appl Probab., Imperfect repair, 20, 851-859 (1983)

6. H. Pham, H. Wang, Eur. J of Oper. Res., Imperfect maintenance, 94, 425-438 (1996)

7. L. Tadj, M. S. Ouali, S. Yacount, D. Ait-Kadi, Replacement Models with minimal Repair, Chapter: A Survey of Replacement Models with Minimal Repair, Springer Verlag (2011)

8. Cleroux, R.; Dubuc, S.; Tilquin, C. The age replacement problem with minimal repair and random repair costs. Oper. Res. 27, 1158-1167 (1979)

9. Sheu, S.H.; Chien, Y.H. Optimal age-replacement policy of a system subject to hocks with random lead-time. Eur. J. Oper. Res. 159, 132-144 (2004)

10. J.H. Lim, J. Qu, M. J. Zuo, Reliability Eng. and Sys. Safety, Age replacement policy based on imperfect with random probability, 149, 24-33 (2016)

11. L. Knopik, K. Migawa, Maintenance and Reliability, Optimal age-replacement policy for non-repairable technical objects with warranty, 19(2), 172-178 (2017)

12. L. Knopik, K. Migawa, Maintenance and Reliability, Multi-state model of maintenance policy, 20(1), 125-130 (2018)

13. L. Knopik, K. Migawa, Maintenance and Reliability, Semi-Markov system model for minimal repair maintenance, 21(2), 256-260 (2019)

14. F. Grabski, Semi-Markov Processes: Applications in System Reliability and Maintenance, Elsevier (2014)

15. F. Grabski, Semi-Markov models of reliability and maintenance (IBS PAN, 2002)

16. G. Asha, N. N. Unnikrishanan, Int. J. of Reliability, Reliability properties of means time to failure in age replacement models, Quality and Safety Engineering, 17(1), 15$26(2010)$

17. L. Knopik, Control and Cybern., Some results on ageing class, 34(4), 1175-1180 (2005)

18. L. Knopik, Control and Cybern., Characterization of a class of lifetime distributions, 35(2), 1175-1180 (2006) 